\title{
About the likely performance of ground support systems submitted to dynamic loading
}

\author{
D Gaudreau Newmont Goldcorp, Australia
}

\begin{abstract}
This paper presents an update to the approach proposed by Gaudreau et al. (2004) for assessing the performance of tendon support systems subjected to dynamic loading. Initially, the updated approach was developed subsequent to the quasi-static and impact pull-out testing data assembled during the modified cone bolt (MCB) prototype tendon support validation. The technique has subsequently been used to estimate the displacement of tendon support systems when subjected to dynamic loading, using experimental data from the tendon's response to quasi-static loading and its material properties. The proposed displacement evaluation method provides a means of calculating the maximum capacity range of tendons for rockburst support design.
\end{abstract}

Keywords: dynamic testing, impact testing, rockbolt rheological model, rockburst, rockbolt

\section{$1 \quad$ Tendon support impact testing approach}

Increasing capacity demands upon ground support systems for challenging ground conditions have resulted in the development of innovative tendon support designs, such as the energy-absorbing rockbolts described in Li (2010), Li \& Doucet (2012) and Li et al. (2014). As most tendons can be stressed in axial loads far past their elastic limits, we are challenging our understanding of the performance of such systems. Similarly, under those high-stress conditions, it may be impracticable to derive design parameters from in situ pull-out testing, because such testing would need to be conducted under potentially hazardous conditions.

An increasing amount of impact testing on tendon support is conducted by the industry to inform practitioners about the likely performance of those elements under similar conditions. Conceptually, the aim is to stress the tendon in a way that is deemed similar to that which would be encountered in the field. However, interpreting the test results is difficult because the various testing apparatus and assemblies constrain the tendon support elements in different ways. For example, it is difficult to ascertain how the performance of a tendon support element under impact loading in a split-tube test configuration compares with that of a direct impact test when comparing energy-absorption performance.

Several testing apparatus are described in the literature. Plouffe et al. (2008) describe the impact test rig used at CANMET-MMSL laboratories in Canada. Player et al. (2008) describe the apparatus used at the WASM laboratory facilities in Australia, and present a critical evaluation of other test apparatus. In this paper, two general testing approaches are discussed (Figure 1):

- Direct loading (full tube): the tendon support system is stressed by the movement of a mass and an instantaneous impact velocity applied directly to the tendon at the collar. The tendon support system is free to move axially. The outer test tube position is rigidly locked at the distal end.

- Indirect loading (split tube): the tendon support system is stressed by the movement of a mass and an instantaneous impact velocity applied to the split test tube at a designated distance from the collar. The tendon support system is free to move axially. The outer test tube is rigidly locked at the distal end of the split tube, and the tendon collar is constrained by the collar split test tube. 


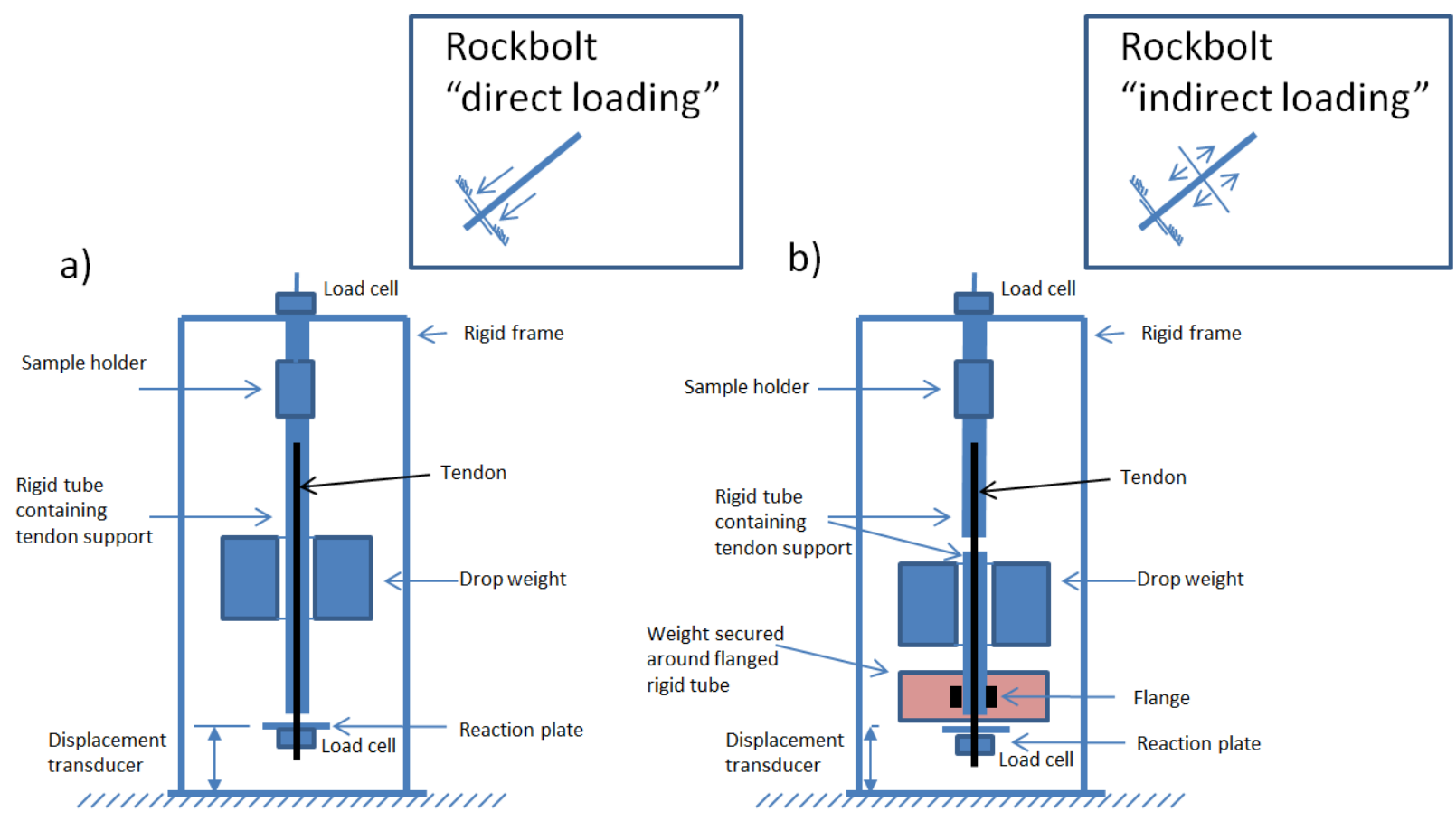

(a)

(b)

Figure 1 Idealised impact test rigs: (a) Direct loading; (b) Indirect loading

Alternative approaches to tendon support impact testing can be conceptualised. Approaches will vary by mass, initial impact velocity and the capacity to pre-tension the tendon. Player et al. (2008) noted some limitations with impact test rigs at the time and were critical of completed tests that used multiple loading cycles on discrete tendon support samples. They argued that material properties change with increased strain rate, that dynamic friction can reduce with velocity increase and that the effective sample configuration changes after each loading cycle. For instance, the decoupled length increases near the simulated discontinuity for an indirect loading test. Thus, they were seeking an approach whereby tendons would be tested to destruction with the presence of a simulated discontinuity in impact loading with one testing cycle. They were also keen to prevent the impact mass from 'bouncing' on the reaction plate and to ensure that tests were conducted with pre-tensioned surface hardware to better reflect in situ conditions.

The test results presented by Gaudreau (2004) indicated that the tendon support system's response differs as a function of the impact mass and impact velocity. Their work showed that the oscillatory movement could be a function of the dynamic load transfer through the tendon support system. They observed that the 'bouncing' following the elastic recovery of the tendon had no effect upon the tendon capacity being tested.

\section{$2 \quad$ Characterising the likely performance of tendon support systems under impulsive loads}

Aydan (2018) considered the dynamic response of yielding rockbolts under impulsive loads with a visco-elastic response before yielding and elasto-visco-plastic response after yielding. This paper builds upon this and explores other important considerations for ground support design under impulsive loads, hinging upon the support systems' material properties to characterise its loading capacity and performance:

- In static axial and shear loading.

- In direct and indirect dynamic loading. 


\subsection{Performance of support in static axial and shear loading}

The following are material strength definitions adapted from Amiss et al. (2000) for tendon support elements (Figure 2).
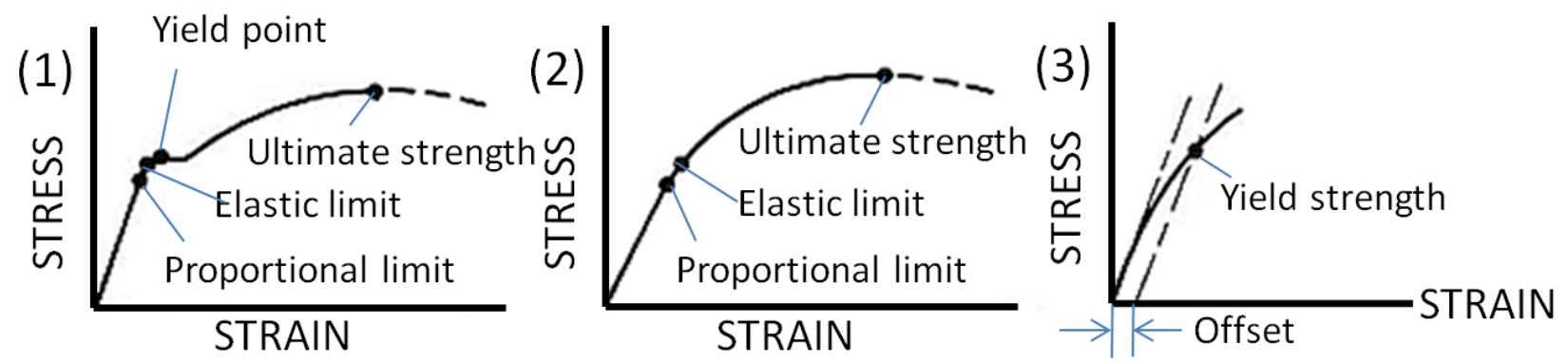

Figure 2 Material characteristics (after Amiss et al. 2000)

Elastic limit: the maximum stress to which a rockbolt may be subjected and return to its original length upon release of the load. A rockbolt is said to be stressed within the elastic region when the working stress does not exceed the elastic limit, and to be stressed in the plastic region when the working stress does exceed the elastic limit. The elastic limit for steel is approximately the same as its proportional limit.

Yield point: the point on the stress-strain curve at which there is a sudden increase in strain without a corresponding increase in stress.

Yield strength and yield stress $\sigma_{\mathbf{y}}$ : the maximum force and stress than can be applied without permanent deformation of the rockbolt. This is the value of the stress at the elastic limit for steel. Some bolt manufacturers apply an offset method to calculate the yield strength rather than directly using the yield point. For example, the yield strength stress value could correspond to $0.1 \%$ of the permanent original strain dimension.

Ultimate strength (also called ultimate tensile strength [UTS]): the maximum stress value obtained on a stress-strain curve. A Factor of Safety of 1.1 is most often applied to values provided by rockbolt distributors. Some of the applicable standards for UTS, $\sigma_{y}$, and \% strain are AS/NZS 4671:2001 (Standards Australia 2001), ASTM A416 (ASTM International 2006) and CSA G30.18-09 (R2014) (CSA Group 2014).

Modulus of elasticity E (Young's modulus): the ratio of unit stress to unit strain within the proportional limit of a rockbolt in tension.

Modulus of elasticity in shear $\mathbf{G}$ (bulk modulus): the ratio of unit stress to unit strain within the proportional limit of a material in shear.

Shear strength: the shear capacity of the rockbolt. The pure shear capacity of a rockbolt is a function of its yield strength based on the relationship, derived from the von Mises yield criterion:

$$
\text { Pure shear strength }=\frac{\text { Yield strength }}{\sqrt{3}}
$$

The pure shear strength capacity is calculated differently depending on rockbolt distributors, whereby a safety factor of 1.1 to 1.2 is applied representing for some distributors $\sim 58 \%$ of $\sigma_{y}$ for the minimum point and $\sim 65 \%$ of $\sigma_{y}$ for the typical point, whereas other distributors use $70 \%$ of UTS, which is roughly $85 \%$ of $\sigma_{y}$. There is no prescribed standard to quote shear strength figures, thus a critical review of the design parameter is warranted by the ground support system design practitioner.

Dynamic energy absorption: the work energy consumed by the tendon support system. Energy, force and bolt displacement values for impact tests are not governed by national standards presently. Thus, specification sheets issued by rockbolt distributors or manufacturers may contain information pertaining to a single impact test, which may be an extrapolation of quasi-static pull-out testing, a direct impact test (continuous tube) or an indirect impact test (split tube). The information pertaining to the rockbolt length, 
impact mass and velocity is often missing, and the energy calculation method may often not include work energy-for example, it is extrapolated from potential energy, without the addition of the work energy contribution due to the bolt displacement.

Length mobilised: the portion of the tendon support that is effectively strained by the loading system.

Bolt modulus: the modulus of elasticity of the tendon support system, and the ratio of stress to strain. Typical rock tendon behaviour under quasi-static loading shows an elastic displacement phase and a plastic displacement phase. For the benefit of this paper, the idealised tendon reaction is considered to have an elastic stiffness $\mathrm{K}_{\mathrm{e}}$ and a plastic stiffness $\mathrm{K}_{\mathrm{p}}$ (Figure 3). Some permanent displacement is said to occur when a tendon has been pulled past its elastic displacement range into its plastic deformation range. The plastic stiffness $K_{p}$ can be measured in quasi-static pull tests and will be affected by the length of the tendon actually exposed to the load. As the tendon must be pulled well into its plastic deformation, carrying out the test can be hazardous. As an alternative, the bolt parameters can be derived from the following equations and guided by the rockbolt distributor's material specifications:

Displacement at yield $=$ Length mobilised $\cdot$ tendon \% elastic strain specification

Displacement at peak $=$ Length mobilised $\cdot$ tendon \% plastic strain (no necking) specification

$$
\begin{gathered}
\mathrm{k}_{\mathrm{e}}=\frac{\text { Yield strength }}{\text { Displacement at yield }} \\
\mathrm{k}_{\mathrm{p}}=\frac{\text { Ultimate tensile strength-Yield strength }}{\text { Displacement at peak-Displacement at yield }} \\
\text { Bolt modulus }=\frac{\mathrm{k}_{e} \text {. Length mobilised }}{\text { Surface area }}
\end{gathered}
$$

Displacement capacity static loading at UTS $=\frac{\text { Yield strength }}{\mathrm{k}_{e}}+\frac{\text { UTS-Yield strength }}{k_{p}}$

$$
\text { Displacement capacity static loading at shear }=\frac{\text { Pure shear strength }}{\mathrm{k}_{e}}
$$

Work energy static loading $=($ Displacement at peak - Displacment at yield $) \cdot \frac{\text { Yield strength }}{2}+$

(Displacement at peak - Displacement at yield) $\frac{\text { (UTS-Yield Strength) }}{2}+$ Yield strength .

(Displacement at peak - Displacement at yield)

The bolt material properties produced in this document have been formulated from manufacturer's specification data, in situ through pull-out tests (POTs), and validated from direct and indirect impact tests available. They are, however, only indicative and provided for the purpose of supporting the narrative.

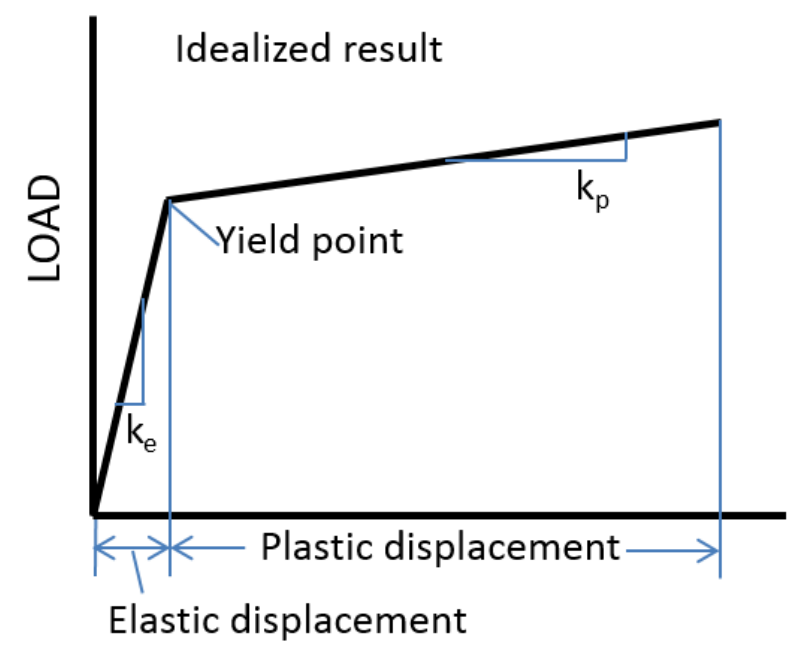

Figure 3 Schematic of typical pull test result curve (Gaudreau 2004) 


\subsection{Shear strength capacity of rockbolts}

Rockbolts in a ground support system must perform in static axial and shear loading. The shear strength capacity of rockbolts is rarely a function of pure shear strength alone, as the loading mechanism often allows for some combination of tensile and shear stresses. Hence, a literature review was conducted to critically assess the shear strength capacity of rockbolts. Aziz et al. (2003) conducted double shear testing on fully grouted and axially tensioned bolts installed in two different types of three-piece concrete blocks (Figure 4). The purpose of the study was to examine the behaviour of reinforced bolts in shear under different axial loading conditions. A total of 22 bolts were tested using three common types of bolts that are used in Australian coal mines. The differentiating factor for the rockbolts was mainly the surface profile configuration and the role of such configuration on the load transfer characteristic of cement/resin and bolt interactions. The influence of different tensional loads on the load transfer characteristics of bolts was also examined. The shear loads were found to increase with increasing tensional loads, and the bolt profile configuration had influenced the shear load. During the experimental set-up for this program of study, the $150 \mathrm{~mm}^{2}$ side blocks were found to be relatively small and inadequate for conducting tests of relatively large bolt size and load application magnitudes for the double shear testing.
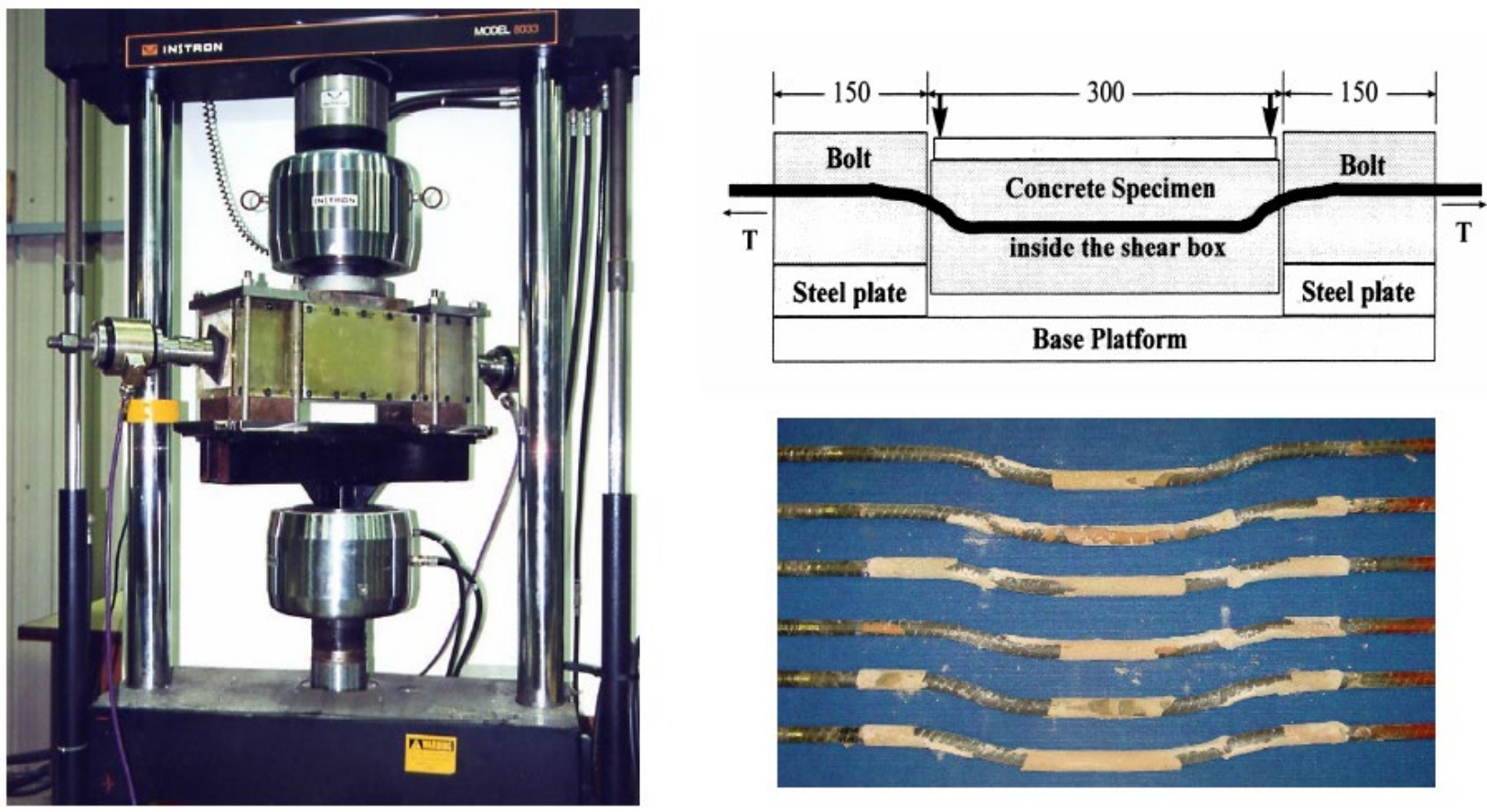

Figure 4 Photograph of tested sample in Instron testing machine and sketch of deformed $22 \mathrm{~mm}$ rebar bolts together with a number of post-testing deformed bolts (Aziz et al. 2003)

Aziz et al. (2015) conducted further double shear test experiments using a press of higher capacity (Figure 5). The objective was to investigate the performance of $22 \mathrm{~mm}$ diameter, 60 tonne tensile strength capacity Hilti cable bolts. Testing was conducted using a double shear testing apparatus located at the University of Wollongong. The tested cable bolts were Hilti 19 wire HTT-UXG plain strand and Hilti 19 wire HTT-IXG spirally profiled. Each cable bolt was pre-tensioned to $50 \mathrm{kN}$ axial force. A 500 tonne capacity Avery servocontrolled compression testing machine was used for both tests; during each test, the vertical shear displacement was limited to $70 \mathrm{~mm}$ of travel. The maximum shear load achieved for the plain strand cable was $1,024 \mathrm{kN}$, while the spiral cable peak load was $904 \mathrm{kN}$, before the cable bolt wires began to individually snap, leading to the cable bolt breaking up into two sections. It was apparent that spiral profiles of the outer wires weaken both the tensile and shearing strength. 


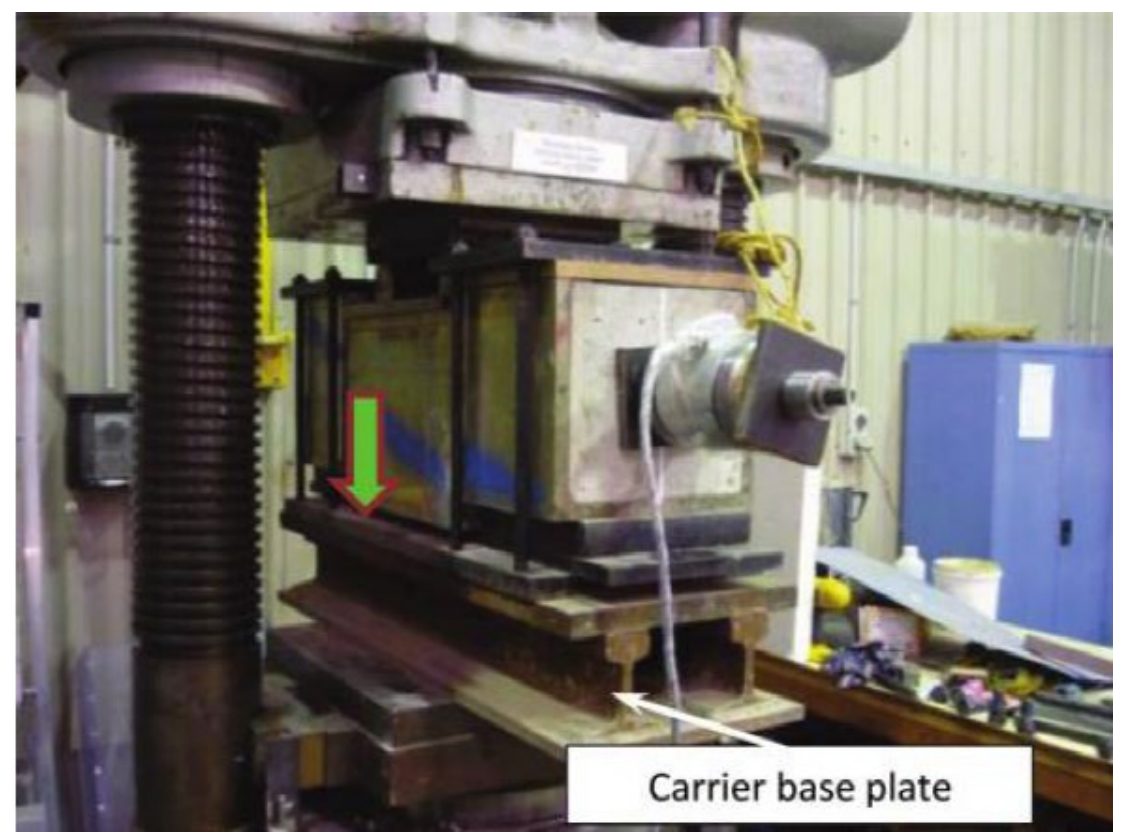

Figure 5 Double shear apparatus loaded in 500 t Avery compression testing machine (Aziz et al. 2015)

Here, I calculate the shear performance of the cable bolts based on the information provided in the paper. Table 1 presents the data retrieved from the paper and the calculated pure shear and inferred single plane shear load at peak. The experiments conducted showed damage to the concrete blocks following the shear tests (Figure 6a). Furthermore, the failed cable wire ends showed a combination of tensile and shear failures (Figure $6 \mathrm{~b}$ ). The author attributed this mixed failure mode to the result of the bending of the cable near the shear planes where the concrete has crushed. As indicated in Table 1, the pure shear strength of the cable, estimated from the ultimate yield strength, is lower than the actual measured shear strength at peak. In this case, the inferred mixed axial and shear strength at peak, estimated to be half of the measured shear load to represent a single shearing plane, is $\sim 12 \%$ lower than the ultimate axial failure load of the cable for each cable type. If a pure shear mechanism were present, the shear strength would be $\sim 42 \%$ lower than the yield load or $\sim 50 \%$ lower than the ultimate failure load.

Table 1 Hilti HTT-UXG 19 strand cable bolt double shear test analysis

\begin{tabular}{lll}
\hline Parameter & Plain strand & Spiral strand \\
\hline Ultimate yield strength $(\mathrm{kN})$ & 495 & 425 \\
Ultimate tensile strength $(\mathrm{kN})$ & $\mathbf{5 7 3}$ & $\mathbf{5 1 0}$ \\
Bolt diameter $(\mathrm{mm})$ & 21.8 & 21.8 \\
Cross-sectional area $\left(\mathrm{mm}^{2}\right)$ & 312.9 & 277 \\
Measured axial load at peak $(\mathrm{kN})$ & 400 & 254 \\
Measured shear load at peak $(\mathrm{kN})$ & 1,024 & 904 \\
\hline Calculated parameters & & \\
\hline Calculated pure shear strength (kN) & $\mathbf{2 8 5}$ & $\mathbf{2 4 5}$ \\
Inferred single plane shear load at peak (kN) & $\mathbf{5 1 2}$ & $\mathbf{4 5 2}$ \\
\hline
\end{tabular}




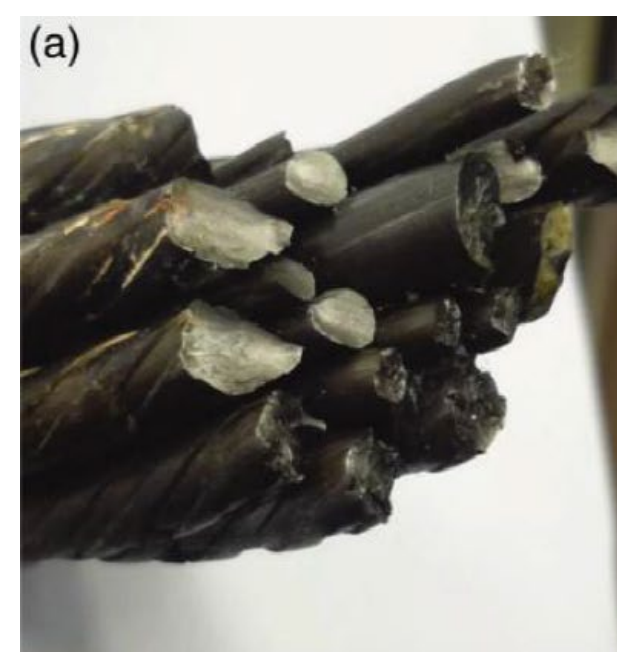

(a)

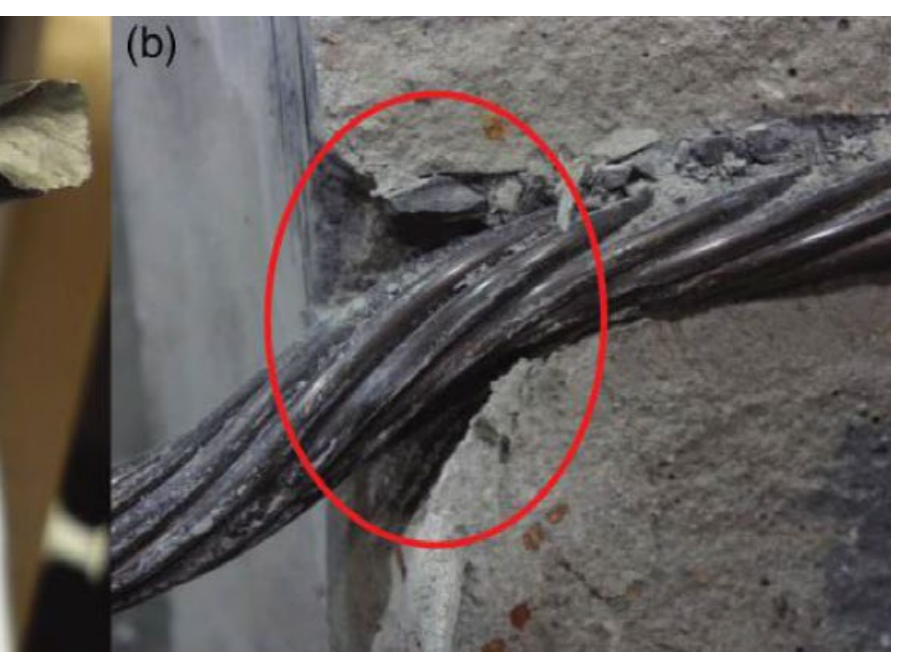

(b)

Figure 6 (a) Failed spiral strand cable bolt; (b) Concrete deformation around sheared section of bolt (Aziz et al. 2015)

Li (2016) conducted investigations into shear performance of rockbolts under static and dynamic loading conditions. The aim of his thesis was to provide a detailed analysis of shear behaviour of rockbolts by using laboratory tests and numerical modelling approaches. A double shearing test system was used to examine the performance of rockbolts under shearing loads. The laboratory test results indicate that rock strength, rockbolt diameters and installation angles affect the shear resistance of the double shear test system. Of interest, Li compared the double shear test results under static and dynamic loading conditions. He found that the energy-absorption ability of rockbolts under dynamic double shear loading is lower than under the static loading condition. By confining the concrete blocks (Figure 7), Li managed to conduct double shear tests to failure.

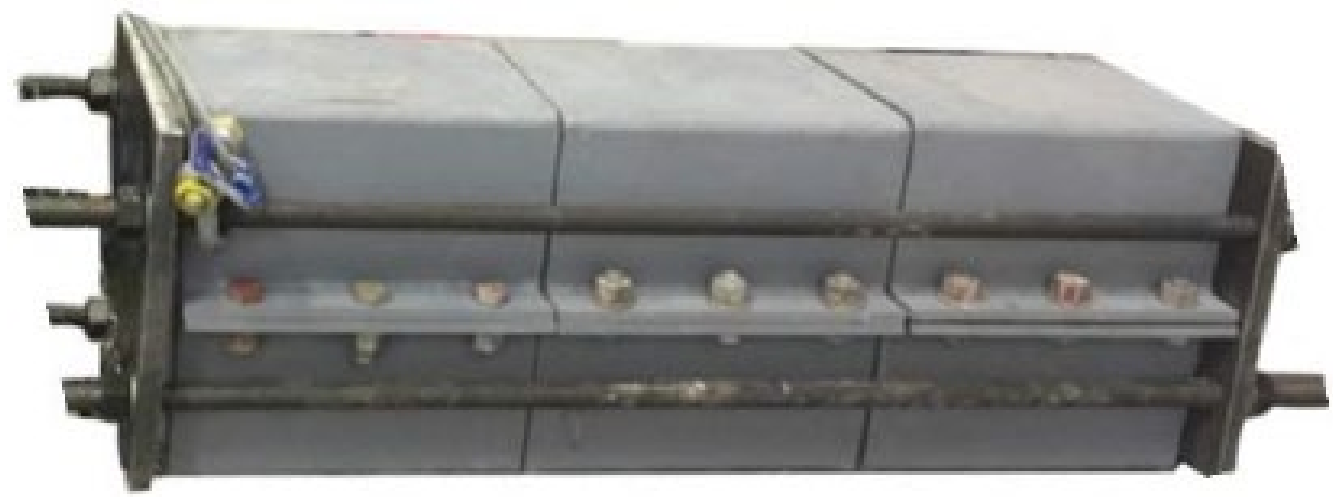

Figure 7 Fully confined double shear sample (Li 2016)

The static results are presented in Table 2, along with calculations made for this paper. The figures indicate the $16 \mathrm{~mm}$ bar shear strength closely matches that of the UTS, whereas the $8 \mathrm{~mm}$ bar shear strength exceeds the UTS. The $8 \mathrm{~mm}$ bar may have crushed the cement-holding matrix.

Impact double shear tests were conducted by Li (2016) using the apparatus illustrated in Figure 8 . The apparatus was not of sufficient size to test $16 \mathrm{~mm}$ bar to rupture. The $8 \mathrm{~mm}$ bar results suffered from the same issues as the static double shear tests, in which the concrete matrix was damaged leading to mixed-mode rupture of the bar. 
Table 2 Double shear static results from Li (2016) and additional calculated values

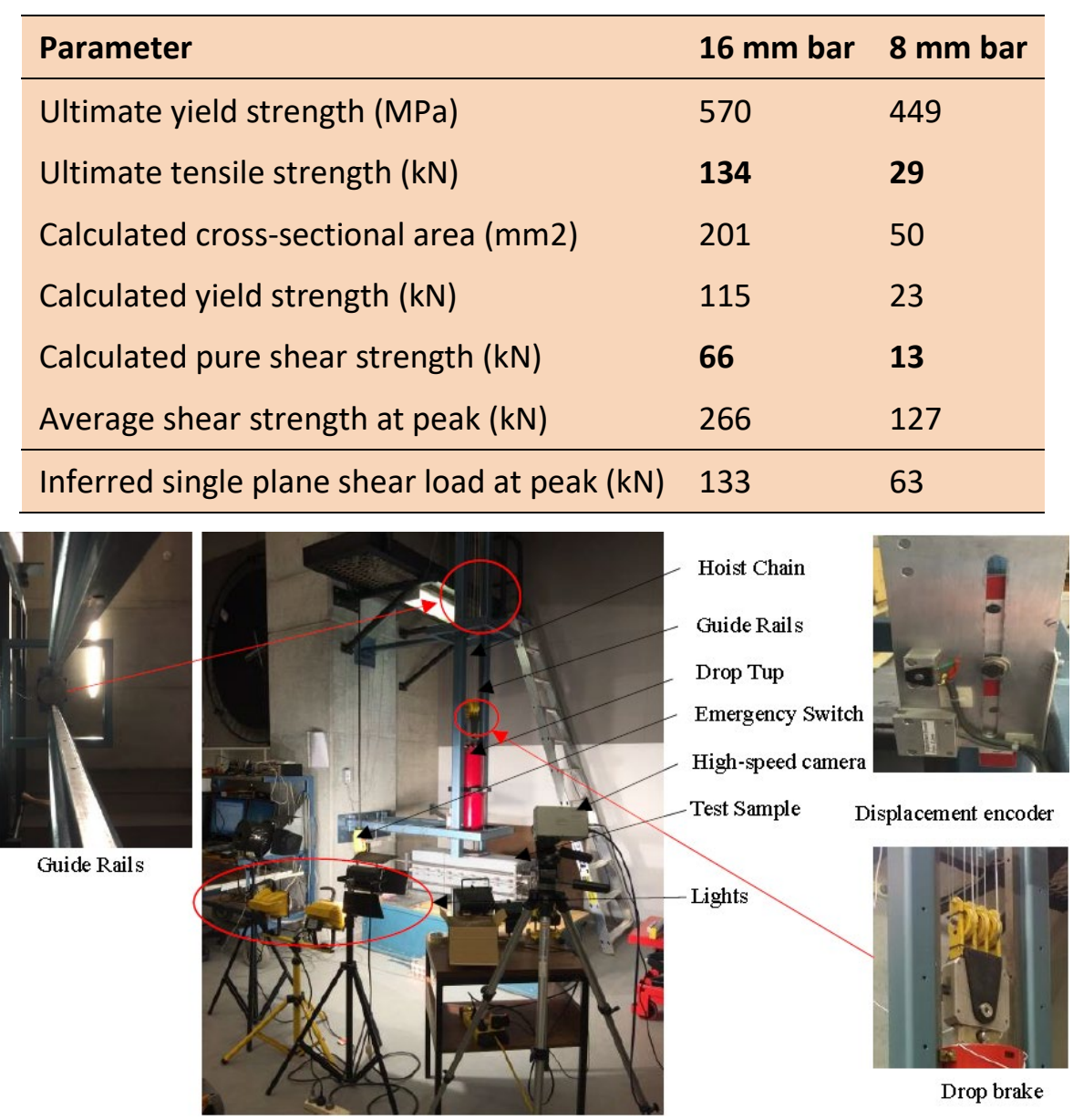

Figure 8 Dynamic double shear test apparatus (Li 2016)

Chen (2014) conducted various experiments on rebar and D-bolts to characterise their performance, notably in mixed axial and shear loading. Both the rebar bolt and D-bolt specimens were $20 \mathrm{~mm}$ in diameter and $2 \mathrm{~m}$ in length with a thread section of 150-200 $\mathrm{mm}$ at one end. The D-bolt specimens had two anchor points that were spaced by a distance of $1 \mathrm{~m}$. Five displacing angles between full axial and full tangential angles were employed in the tests. The experimental results show the strength of the concrete or concrete-granite blocks hosting the samples has an effect on the test results. The ultimate displacement of the rockbolt was greater in the weak blocks than in the strong blocks. Bolt bending is significantly large when the bolt is subjected to stronger rocks. This has had an impact upon combined axial and shear performance of the bolt.

Chen \& Li (2015) conducted further analysis and observed that the linear elastic stiffness of both the D-bolt and a rebar profile bolt is mobilised after a small displacement. When the displacing angle was larger than $40^{\circ}$, grout crushing occurred underneath the bolt shank, resulting in the reduction of the bolt system modulus, which was favourable to the bolt performance. Furthermore, it was observed that the ultimate strength of the bolts remained relatively the same while varying the displacement angle, for both the Dbolt and the rebar bolt (Figure 9a). As such, the materials were not tested in 'pure shear', as defined in this paper, but under a combination of shear and axial load, and the worst material performance was $175 \mathrm{kN}$, which is $\sim 16 \%$ lower than the UTS specification under elongation for these bolts.

The displacement capacity of the D-bolt was found to be more significantly dependent on the angle of displacement (Figure 9b). The ultimate displacement of a 1-m long D-bolt section varies from $140 \mathrm{~mm}$ under axial pull $\left(0^{\circ}\right)$ to approximately $70 \mathrm{~mm}$ when the angle of displacement is larger than $40^{\circ}$. The ultimate displacement of the rebar slightly increases from $29 \mathrm{~mm}$ under axial pull to $53 \mathrm{~mm}$ under 
tangential shear. In general, the displacement capacity of the D-bolt is larger than that of the rebar bolt. It is approximately 3.5 times that of the rebar under axial pull and $50 \%$ higher than rebar under shear displacement.

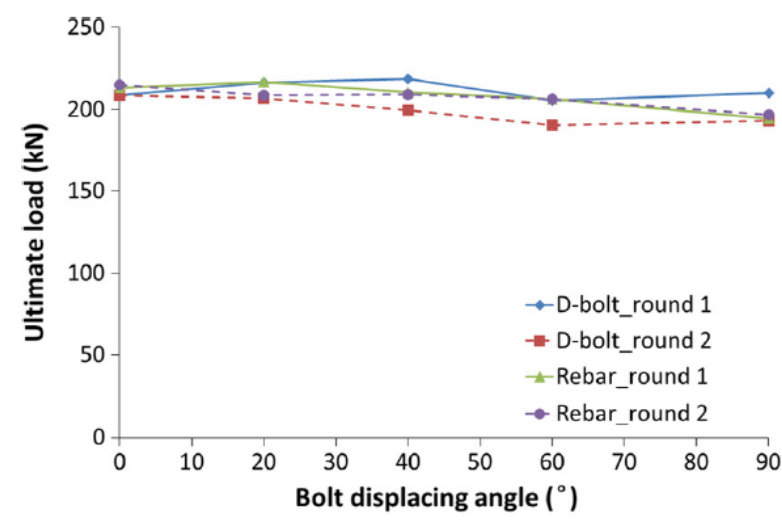

(a)

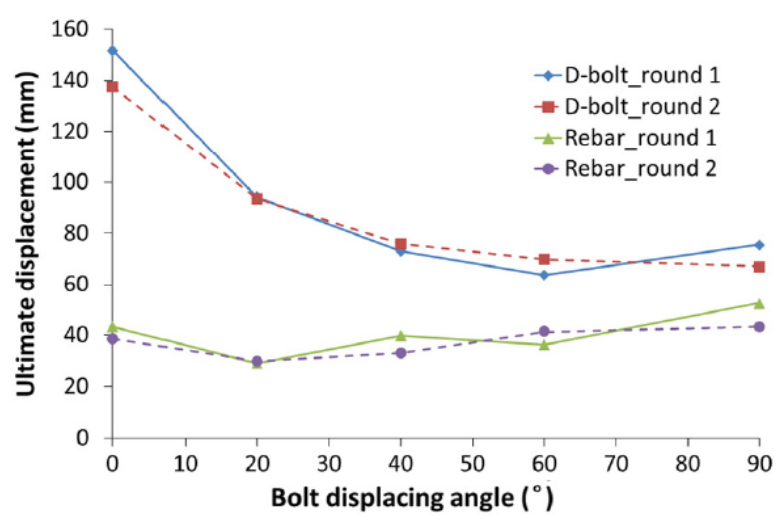

(b)

Figure 9 Ultimate load and ultimate displacement versus the displacing angle for the D-bolt and rebar specimens: (a) Ultimate load; (b) Ultimate displacement (Chen \& Li 2015)

Grasselli (2005) conducted double shear tests onto $16 \mathrm{~mm}$ and $20 \mathrm{~mm}$ bolts as well as Swellex bolts. The analysis of the results obtained from finite element modelling, and from large-scale (1:1) shear tests for fully grouted rebar and Swellex bolts, show that the two bolt types deform in dissimilar ways. The author attempted to distinguish the bolt's contribution to the combined axial and shear loading capacity by separating the effects of friction from those of bolt forces internal to the bolt. It was observed that the amount of grout crushing and the shape of the bolt affected the capacity of the full steel bolt to mobilise $85-95 \%$ of the UTS, against only $65-75 \%$ of the frictional one.

Gillerstedt (1999) conducted single shear testing upon rebar and cone bolts. The experimental set-up is illustrated in Figure 10. Photos of the three sheared bolt samples are shown in Figure 11. The results analysis (Tables 3, 4 and 5) indicates that the ultimate combined shear/tension strength is the same as the UTS of the steel. However, the total displacement of the bolt in shear is at least $50 \%$ of the expected displacement in axial loading only.

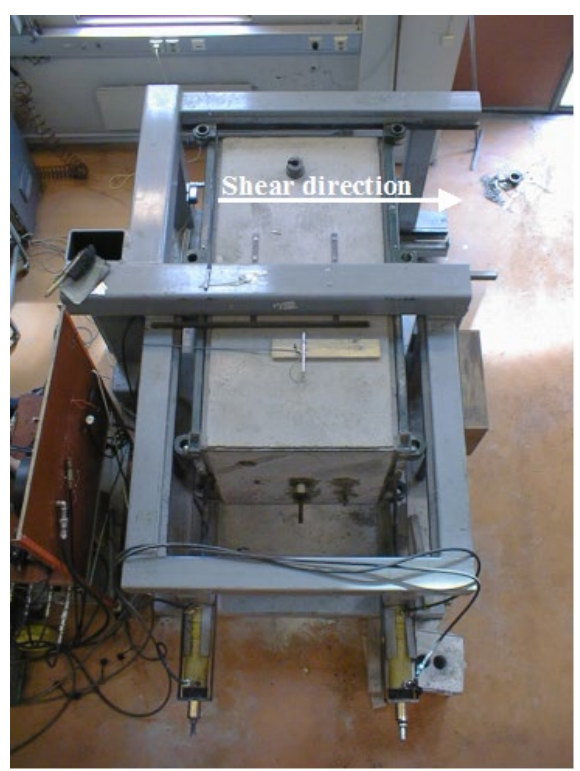

Figure 10 Test rig for single shear test (Gillerstedt 1999) 


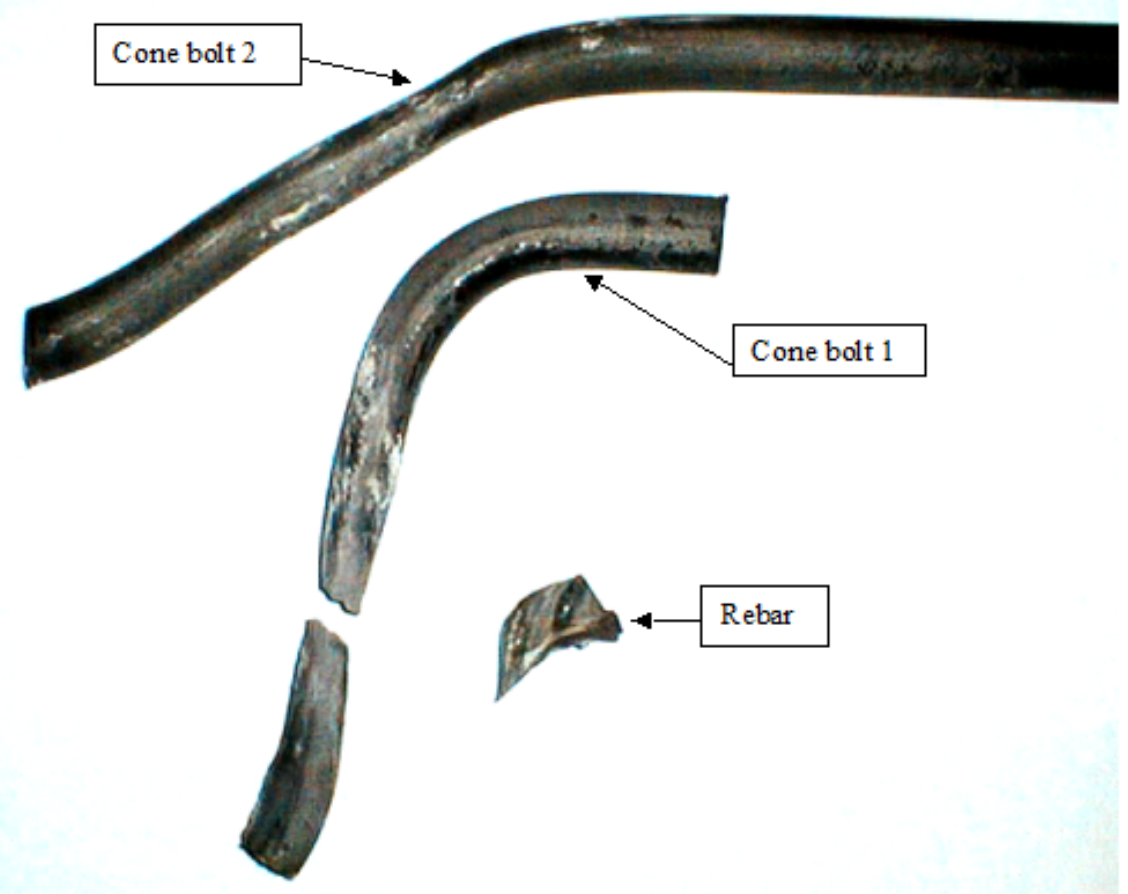

Figure 11 Sheared bolt samples (Gillerstedt 1999)

Table 3 Pull testing of cone bolts based upon Gillerstedt (1999)

\begin{tabular}{llllll}
\hline $\begin{array}{l}\text { Mixture number and } \\
\text { grout strength (MPa) }\end{array}$ & $\begin{array}{c}\text { Yielding } \\
\text { force }\end{array}$ & $\begin{array}{c}\text { Total displacement } \\
\text { of plate }\end{array}$ & $\begin{array}{c}\text { Total displacement } \\
\text { of cone }\end{array}$ & $\begin{array}{c}\text { Elongation of } \\
\text { bolt }\end{array}$ \\
\cline { 2 - 7 } & $\mathbf{( k N )}$ & $\mathbf{( m m )}$ & $\mathbf{( m m})$ & $\mathbf{( m m )}$ & $\mathbf{( \% )}$ \\
\hline$\# 1 / 28$ & $120-130$ & 245 & 241 & 4 & 0.3 \\
$\# 2 / 35$ & $135-145$ & 246 & 226 & 20 & 1.5 \\
$\# 3 / 47$ & $140-150$ & 240 & 211 & 29 & 2.1 \\
\hline
\end{tabular}

Table 4 Shear testing results of cone bolts from Gillerstedt (1999)

\begin{tabular}{lccccccc}
\hline Bolt & $\begin{array}{c}\text { Compressive } \\
\text { strength of } \\
\text { grout }\end{array}$ & $\begin{array}{c}\text { Max. } \\
\text { shear } \\
\text { load }\end{array}$ & $\begin{array}{c}\text { Max. shear } \\
\text { displacement }\end{array}$ & $\begin{array}{c}\text { Cone/end } \\
\text { displacement }\end{array}$ & $\begin{array}{c}\text { Joint } \\
\text { opening }\end{array}$ & $\begin{array}{c}\text { Axial load at } \\
\text { bolt head }\end{array}$ & Result \\
\cline { 2 - 6 }$(\mathbf{M P a})$ & $(\mathbf{k N})$ & $(\mathbf{m m})$ & $(\mathbf{m m})$ & $(\mathbf{m m})$ & (kN) & \\
\hline $\begin{array}{l}\text { Cone } \\
\text { bolt 1 }\end{array}$ & 69 & 268 & 226 & 69 & 6,5 & $75-84$ & Bolt failed \\
$\begin{array}{l}\text { Cone } \\
\text { bolt 2 }\end{array}$ & 28 & 244 & 225 & 107 & 7 & $71-84$ & Block failed \\
Rebar 69 & 230 & 43 & 0 & $0+$ & 1 & Bolt failed \\
\hline
\end{tabular}


Table 5 Calculated results after Gillerstedt (1999) experiments

\begin{tabular}{lll}
\hline & $\mathbf{2 2} \mathbf{~ m m}$ cone bolt & $\mathbf{2 0 ~} \mathbf{~ m m}$ rebar \\
Ultimate strain value (\%) & 20 & 17 \\
Yield strength (MPa) & 260 & 570 \\
Ultimate stress value (MPa) & 600 & 670 \\
Modulus of elasticity (GPa) & 200 & 210 \\
Calculated yield strength (kN) & 81 & 179 \\
Calculated UTS (kN) & 188 & 210 \\
Calculated UTS (kN) FS = 1 & 270 & 231 \\
Ratio of max shear: UTS & 1.00 & 1.02 \\
\hline
\end{tabular}

Based upon the literature review and the general material characterisation information above, it is clear that:

- A rock shear capacity can be calculated based upon the von Mises yield criterion to provide a lower bound capacity value along with a lower bound bolt displacement capability based upon the bolt modulus.

- The combined shear and tensile ultimate capacity of the bolt over a minimum length mobilised can be calculated to provide an average capacity value from POTs and/or the rockbolt material properties.

\section{Performance of support in direct and indirect dynamic loading}

In the original paper (Gaudreau et al. 2004), an approach was proposed to estimate the likely performance of tendon support under dynamic loading based upon quasi-static pull testing results and the tendon's material properties. Some subsequent amendments were made to the original suggested approach to cater for a broader range of loading mechanisms that can be subsequently verified using rockbolt impact testing in laboratory conditions.

A rockburst may occur when the rock mass hosting underground excavations fails violently under a combination of circumstances, such as the presence of strong and brittle rock subject to high stresses. The phenomenon has been recognised as a high risk in the underground mining industry, and significant advances were made (Kaiser \& Cai 2012) towards real time seismic hazard tracking, the optimisation of mine sequencing and mining methods, and the refinement of ground control and risk hazard management procedures to reduce exposure to rockbursts.

Reinforcement and tunnel support techniques, such as the use of rockbolts, reaction plates and mesh, can be deterministic for gravity-driven situations when the support systems are subjected to static and quasi-static loading. The approach towards the selection of a combination of commercially available ground support elements or the design of fit-for-purpose ground support systems for dynamic loading is less obvious. The mechanism of loading is still disputed. For instance, is the seismic event remote to the rock face? Is the seismic event the actual rockburst?

Published guidelines suggest adopting a tendon burden as well as an arbitrary ejection velocity. These factors can be used to calculate the energy-absorption capacity requirements of a support system so that it can be compared with the work energy during a POT in quasi-static loading mode. In this paper, a different approach is proposed based upon rheological models guiding the assessment of the performance of the tendon support system in various loading modes. 
The proposed calculation method for the displacement evaluation of tendon support submitted to impact loading is based on critically damped harmonic motion (Derrick \& Grossman 1987; Engel 1978; Thomas \& Finney 1992; Van Sint Jan 1994), and it incorporates a so-called friction factor and a yield point offset. The critically damped harmonic motion model consists of a single spring and a dashpot attached to fixed points at each distant end and to a mass at the inner end. A spring and a dashpot in a series constitute a Maxwell model (Gibowicz 1993; Mase 1970). A Maxwell substance, or an elasticoviscous material, behaves differently under rapidly changing stress in contrast with slow loading. The MCB support system behaviour displays this characteristic. The friction factor is a force referring to friction loss and heat dissipation during impact loading; it is not a yield point. Thus, unlike a true Maxwell substance, the proposed model incorporates a combination of the so-called friction force of the tendon in the holding matrix.

The proposed calculation method consists of two main steps. The first relies on a rheological model used to simulate the displacement of a tendon under impact loading. The second involves potential energy and work balanced with the friction factor imparted to the rheological model. The outcome is the approximation of the maximum tendon displacement under impact loading or, alternatively, its maximum axial load for a given mass, impact velocity and characteristic plastic stiffness. The rheological model chosen to simulate the displacement of tendon support under impact loading consists of a mass attached to a slider, a spring and a dashpot in series (Figure 12). The mass $m$ is impacted at initial velocity and displacement $v_{0}$ and $x_{0}$. The spring has a plastic stiffness of $K_{p}$ to which is added a constant yield force of $F_{y}$ when displaced. The dashpot has a damping factor $\mathrm{c}$, proportional to the plastic stiffness of the spring and to the size of the impact mass. Positive displacement $\mathrm{x}$ is downwards.

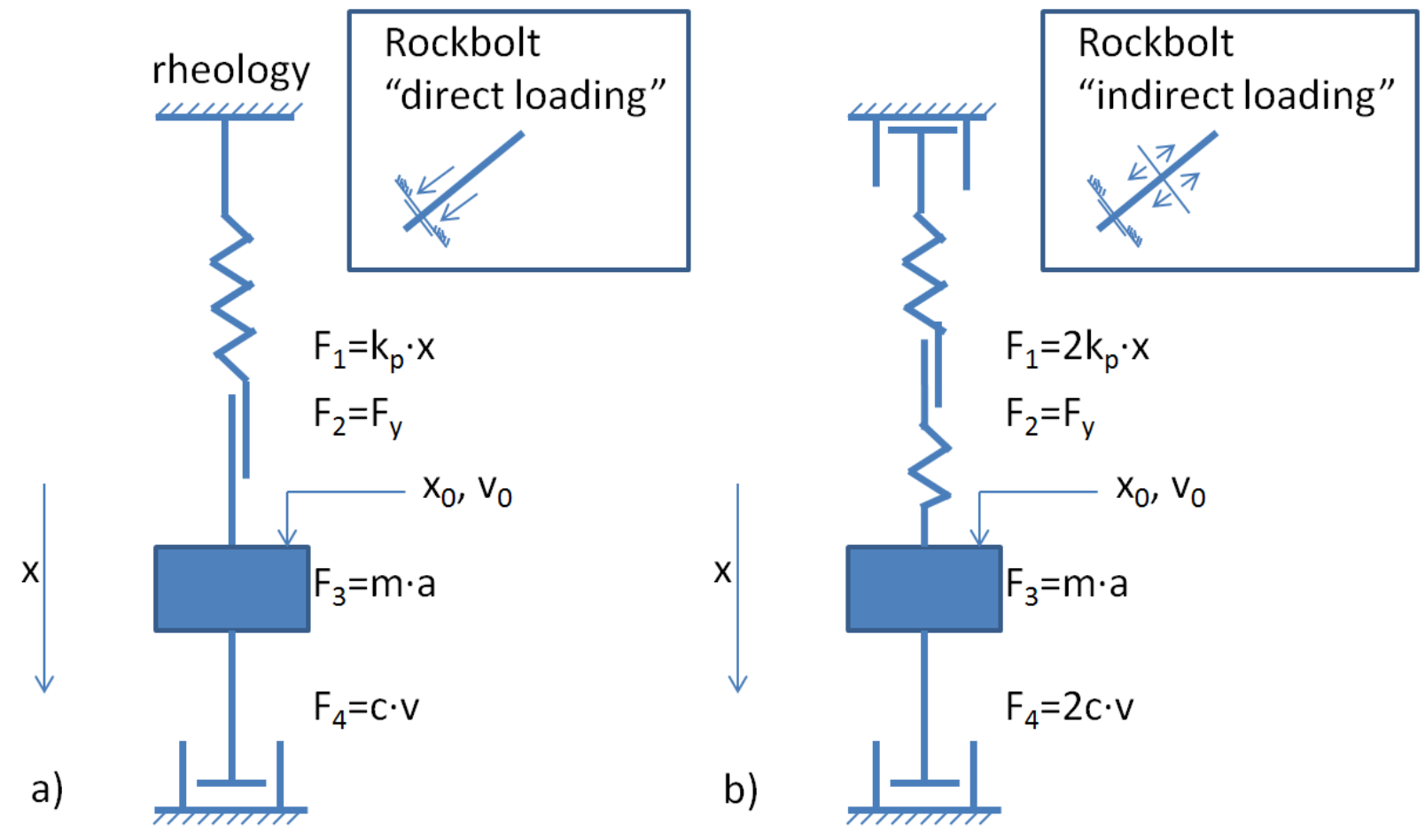

(a)

(b)

Figure 12 Rheological model: (a) Direct loading; (b) Indirect loading 
The overall constant yield force value $\mathrm{F}_{\mathrm{y}}(\mathrm{N})$ for the direct loading case (Figure 12a) and the indirect loading case (Figure 12b) is given by equations (10) and (11) respectively:

$$
\begin{gathered}
F_{y}=\text { Yield strength }+F_{f} \\
F_{y}=3 \cdot \text { Yield strength }+F_{f}
\end{gathered}
$$

where yield strength is the yield load $(N)$ of the tendon material, and $F_{f}$ is the friction factor $(N)$ representing all sources of friction losses.

The model should then require only input parameters that are known a priori from quasi-static pull testing results and specifics, such as the impact mass and initial velocity, the tendon support system plastic stiffness, and the yield load of the tendon material.

Solving the equilibrium of this model (e.g. Figure 12) for forces, we have:

$$
\mathrm{m} \frac{d^{2} x}{d t^{2}}+\mathrm{ic} \frac{d x}{d t}+\mathrm{ik}_{\mathrm{p}} \mathrm{x}+\mathrm{F}_{\mathrm{y}}=0
$$

where $m$ is the mass $(N), c$ is the damping factor, $K_{p}$ is the plastic system stiffness $(N / m)$ as evaluated from pull testing of the tendon, $i$ is a constant of value 1 for direct and 2 for indirect loading, and $F_{y}$ is the overall constant yield force $(\mathrm{N})$ for the displacement of the system, calculated as the addition of the tendon material's yield load and the friction factor (Equations 10 and. 11).

Assuming a critically damped system, the solution to the second-order non-homogeneous differential equation is:

$$
\begin{gathered}
\mathrm{x}_{\mathrm{g}}=\left(\mathrm{C}_{1} \cdot \mathrm{t}+\mathrm{C}_{2}\right) \cdot \mathrm{e}^{-\mathrm{wt}}-\frac{\mathrm{F}_{\mathrm{y}}}{\mathrm{ik_{ \textrm {p } }}} \\
\mathrm{w}=\sqrt{\frac{\mathrm{ik_{ \textrm {p } }}}{\mathrm{m}}} \\
\mathrm{C}_{1}=\mathrm{v}_{0}+\mathrm{w} \cdot\left(\mathrm{x}_{0}+\frac{\mathrm{F}_{\mathrm{y}}}{i \mathrm{k}_{\mathrm{p}}}\right) \\
\mathrm{C}_{2}=\mathrm{x}_{0}+\frac{\mathrm{F}_{\mathrm{y}}}{\mathrm{i \textrm {k } _ { \mathrm { p } }}}
\end{gathered}
$$

where $x_{g}(m)$ is the model's calculated tendon head displacement (Equation 3), $K_{p}(N / m)$ is the plastic stiffness of the tendon support system, $m$ is the mass $(N), x_{0}(m)$ and $v_{0}(m / s)$ are the initial displacement and speed respectively, $t$ is the time (s), and $C_{1}$ and $C_{2}$ are the particular solution constants.

The force in the tendon $\mathrm{F}_{\mathrm{bar}}(\mathrm{N})$ can be calculated using:

$$
\mathrm{F}_{\mathrm{bar}}=\mathrm{x}_{\mathrm{g}} \cdot \mathrm{i} \cdot \mathrm{k}_{\mathrm{p}}
$$

and the potential energy absorption $(\mathrm{J})$ can be calculated as:

$$
\mathrm{E}_{\mathrm{bar}}=\frac{\mathrm{m} \cdot \mathrm{v}_{0}^{2}}{2}+\mathrm{m} \cdot \mathrm{g} \cdot \max (\mathrm{x})
$$

where $g$ is the gravitational constant $\left(\mathrm{m} / \mathrm{s}^{2}\right)$, and $\max x(\mathrm{~m})$ is the maximum displacement calculated.

The work $W_{e}(J)$ required to pull out the tendon in impact load can be calculated from the loaddisplacement graph:

$$
\mathrm{W}_{\mathrm{e}}=\int \mathrm{F} d x
$$

The variables for the rheological model equations (Equations 13 to 16) are parameters $m(N), x_{0}(m)$ and $v_{0}$ $(\mathrm{m} / \mathrm{s})$, which must be defined by the user. The yield load of the tendon material, consisting of part of the overall yield force value $F_{y}(N)$ and the plastic stiffness of the system $K_{p}(N / m)$ are factors specific to the tendon support system. They can be drawn preferably from quasi-static pull testing and materials specifications or, alternatively, from impact tests results. In the latter case, the plastic impact stiffness can be calculated from the end of the load-displacement curve at small impact weight velocity, where the peak 
may appear if the impact load was sufficiently strong enough to deform the tendon. In normal conditions, the initial displacement is set to zero and the initial velocity corresponds to the impact velocity or block ejection velocity. The mass corresponds to the impact weight or the tendon burden.

In order to obtain the axial load in the tendon as well as the energy quantity absorbed through the tendon's movement in impact load, one can follow the following steps (the use of a spreadsheet is recommended):

1. Define an arbitrary friction force $F_{f}$ representing the friction losses and other energy dissipation sources. For the first iteration, it is suggested to use the tendon support system's yield strength measured with pull tests; if not available, the yield strength of the tendon material may be used.

2. Calculate the axial displacement $\mathrm{x}_{\mathrm{g}}$ for different time increments, typically in the order of milliseconds, using Equations 10 or 11, depending on the loading type, and Equations 13 to 16.

3. Calculate the axial force in the tendon $\mathrm{F}_{\text {bar }}$ using Equation 17.

4. Construct a load-displacement graph for the reaction of the tendon. The graph must be set so that if the axial force in the tendon $F_{b a r}$ is not greater than the friction force $F_{f}$, then the force in the tendon $F_{b a r}$ equals the friction force $F_{f}$.

5. Calculate the potential energy dissipated through the tendon $E_{b a r}$ using Equation (18).

6. Calculate the work done during the pull $W_{\mathrm{e}}$ using Equation 19.

7. Repeat steps 1 to 6 until the potential energy Ebar is approximately equal to the work $W_{e}$ by changing the friction force $\mathrm{F}_{\mathrm{f}}$. This can be done in a spreadsheet using a solver function.

The proposed displacement evaluation method can be used to estimate the maximum energy-absorption capacity of a given tendon submitted to impact load in direct or indirect loading. The potential energy absorption of a tendon can be estimated by matching the calculated maximum load to a postulated ultimate tensile capacity of the tendon. The latter can be measured from impact testing or simply taken from the tendon material's specifications.

For example, consider the D-bolt data compiled in Table 6. The rheological modelling approach results are consistent with these published on the D-bolt technical data sheet (Normet 2014; and Figure 13). In this case, note that the tendon is tested beyond its quoted UTS from the material specification. If the tendon is pushed to an axial load of $289 \mathrm{kN}$ as per Figure 14, the energy absorption is a match with $62 \mathrm{~kJ}$. However, the specification sheet does not offer detail on the type of impact testing that was conducted-for instance, split tube or continuous tube (e.g. indirect or direct impact testing). It does not offer detail on the distance between crimps for the bolts. If the practitioner wishes to design the support capacity to the material specification UTS, the energy absorption would lessen to the value indicated in Table 6. Similarly, if the test conducted were a direct loading test at a maximum of $250 \mathrm{kN}$, the result would be similar to that illustrated in Figure 15.

Impact tests can be conducted in different ways. For example, the mass-impact velocity couple can vary significantly between rigs. A more useful representation of impact testing rheological simulation results is shown in Figure 16 and Figure 17. Here the model is solved for a given mass by increasing the impact velocity until the material specification UTS is matched. The limit equilibrium curves can thus be constructed for a given tendon burden to scrutinise the effect of the impact velocity. Note that the impact velocity is not a direct equivalent to the peak ground velocity; the latter would need to be amplified by an amplification factor for design purposes. 
Table 6 Derived dynamic capacity from specification data

\begin{tabular}{lll}
\hline Parameter & D-bolt direct & D-bolt indirect \\
\hline Diameter (mm) & 22.0 & 22.0 \\
Borehole diameter (mm) & $32.5-35.0$ & $32.5-35.0$ \\
Yield strength (kN) & 190.0 & 190.0 \\
Ultimate tensile (kN) & 250.0 & 250.0 \\
Shear strength (kN) & 109.7 & 109.7 \\
Shear strength calculation approach & von Mises & von Mises \\
Length mobilised (m) & $0.4^{*}$ & $0.9 * *$ \\
Strain (\%) elastic & 6.0 & 6.0 \\
Strain (\%) plastic, uniform minimum (no necking) & 15.0 & 15.0 \\
Displacement (m) at yield & 0.024 & 0.054 \\
Displacement (m) at peak & 0.06 & 0.135 \\
Area (mm ${ }^{2}$ ) & 380.1 & 380.1 \\
Bolt elastic stiffness (N/m) Ke & $7.92 \mathrm{E}+06$ & $3.52 \mathrm{E}+06$ \\
Bolt plastic stiffness (N/m) K & $1.67 \mathrm{E}+06$ & $7.41 \mathrm{E}+05$ \\
Bolt modulus (MPa) from POTs for fully bonded model & 8,330 & 8,330 \\
Displacement capacity static loading at UTS (mm) & 60 & 135 \\
Displacement capacity static loading at shear strength (mm) & 14 & 31 \\
Displacement capacity dynamic loading at UTS (mm) & $150^{* * *}$ & $153^{* * *}$ \\
Energy-absorption capacity dynamic loading at UTS (Joules) & $28,400^{* * *}$ & $38,400^{* * *}$ \\
Work energy static loading at UTS (Joules) & 10,200 & 22,950 \\
\hline
\end{tabular}

Note: *based upon distance from nut to collar crimp; ${ }^{* *}$ based upon distance between crimps; ${ }^{* * *}$ for $3,000 \mathrm{~kg}$.

\section{Typical static performance}

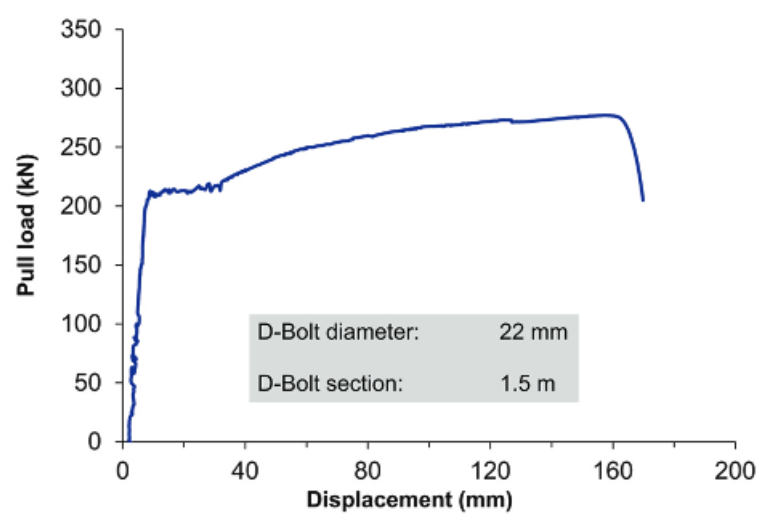

\section{Typical dynamic performance}

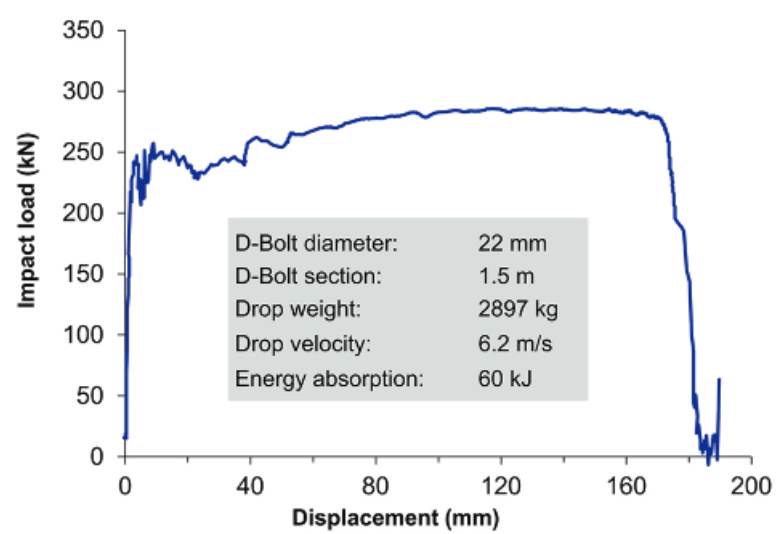

Figure 13 Indirect dynamic loading of D-bolt. Example from Normet (2014) specification sheet 


\section{Calculated tendon axial load vs displacement}

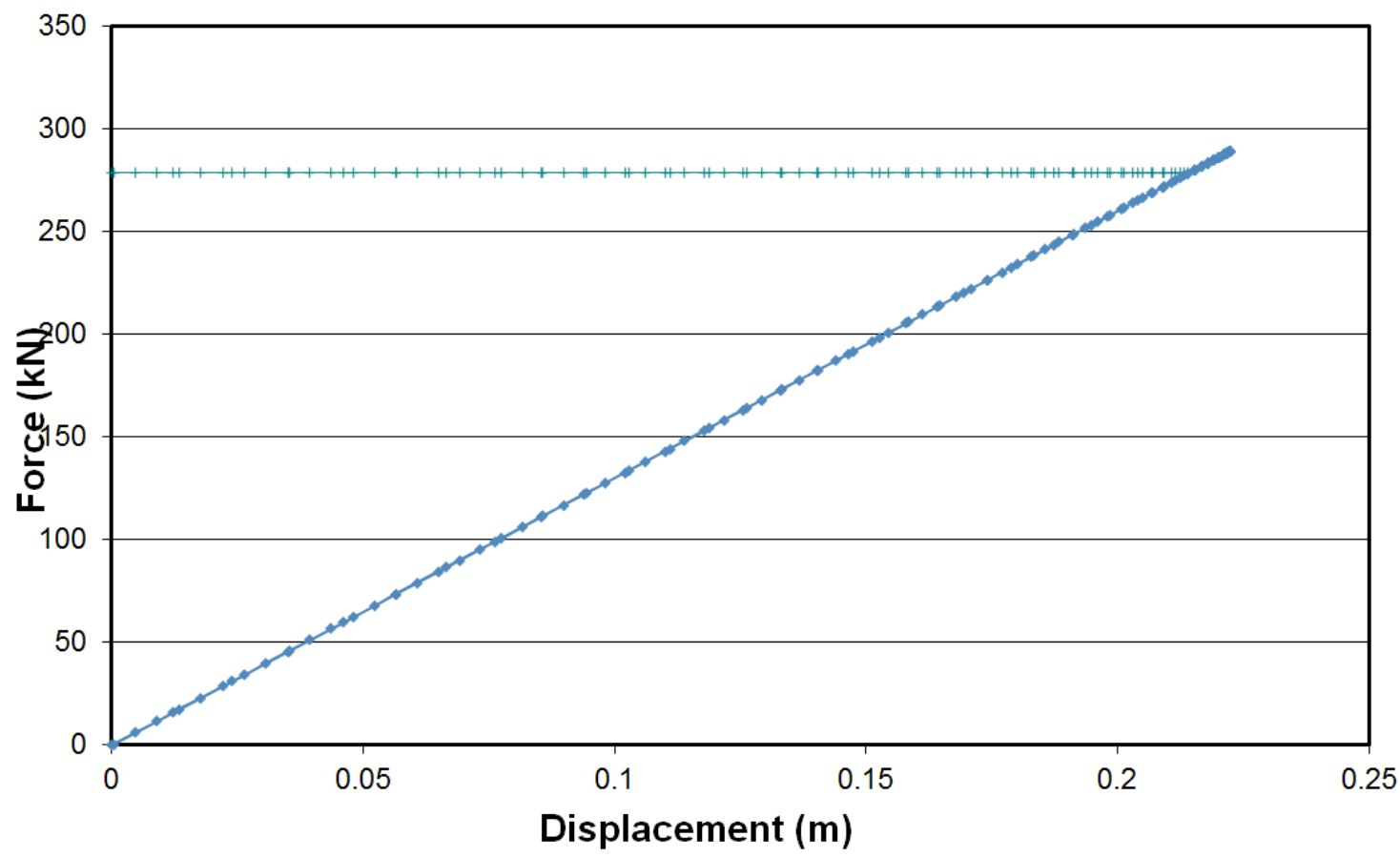

Figure 14 Indirect dynamic loading rheological example load-displacement graph, crimp at $1.0 \mathrm{~m}$ for $\mathrm{K}_{\mathrm{p}}$ of $6.5 \mathrm{E}+5 \mathrm{~N} / \mathrm{m}$, yield point of $1.9 \mathrm{E}+5 \mathrm{~N}$, mass of $2,897 \mathrm{~kg}$ at velocity of $6.2 \mathrm{~m} / \mathrm{s}$

\section{Calculated tendon axial load vs displacement}

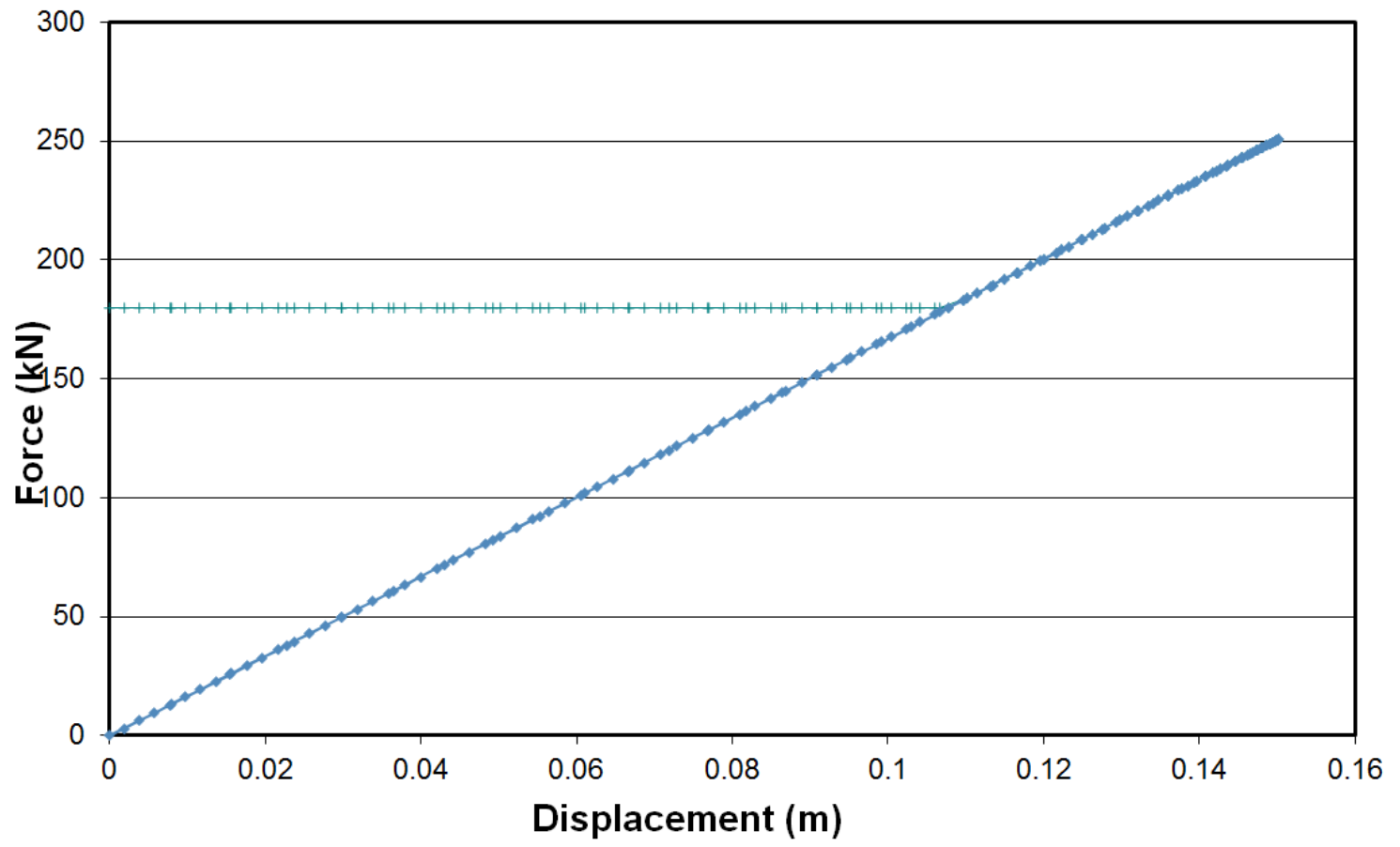

Figure 15 Direct dynamic loading rheological example load-displacement graph, crimp at $0.4 \mathrm{~m}$ from collar for $K_{p}$ of $1.67 \mathrm{E}+6 \mathrm{~N} / \mathrm{m}$, yield point of $1.9 \mathrm{E}+5 \mathrm{~N}$, mass of $3,000 \mathrm{~kg}$ at velocity of $4.0 \mathrm{~m} / \mathrm{s}$ 
Example $15.4 \mathrm{~mm}$ diameter cable bolt - Mine X

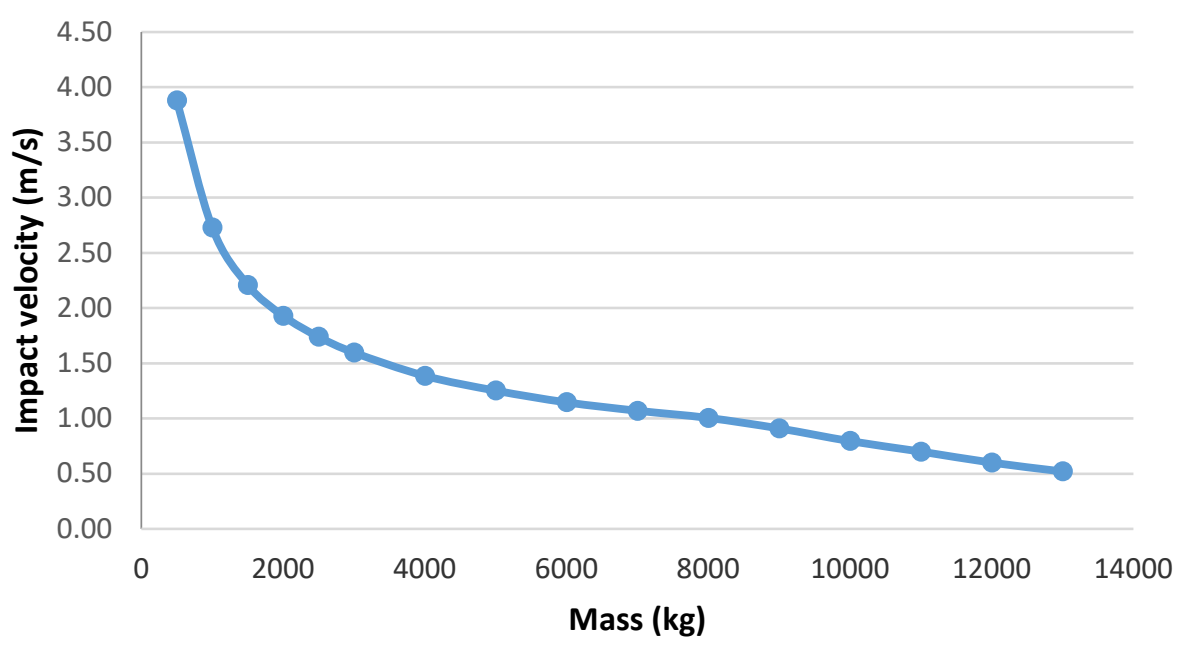

Figure 16 Direct dynamic loading rheological model example, cable bolt maximum load of $260 \mathrm{kN}$

Example $15.4 \mathrm{~mm}$ diameter cable bolt - Mine X

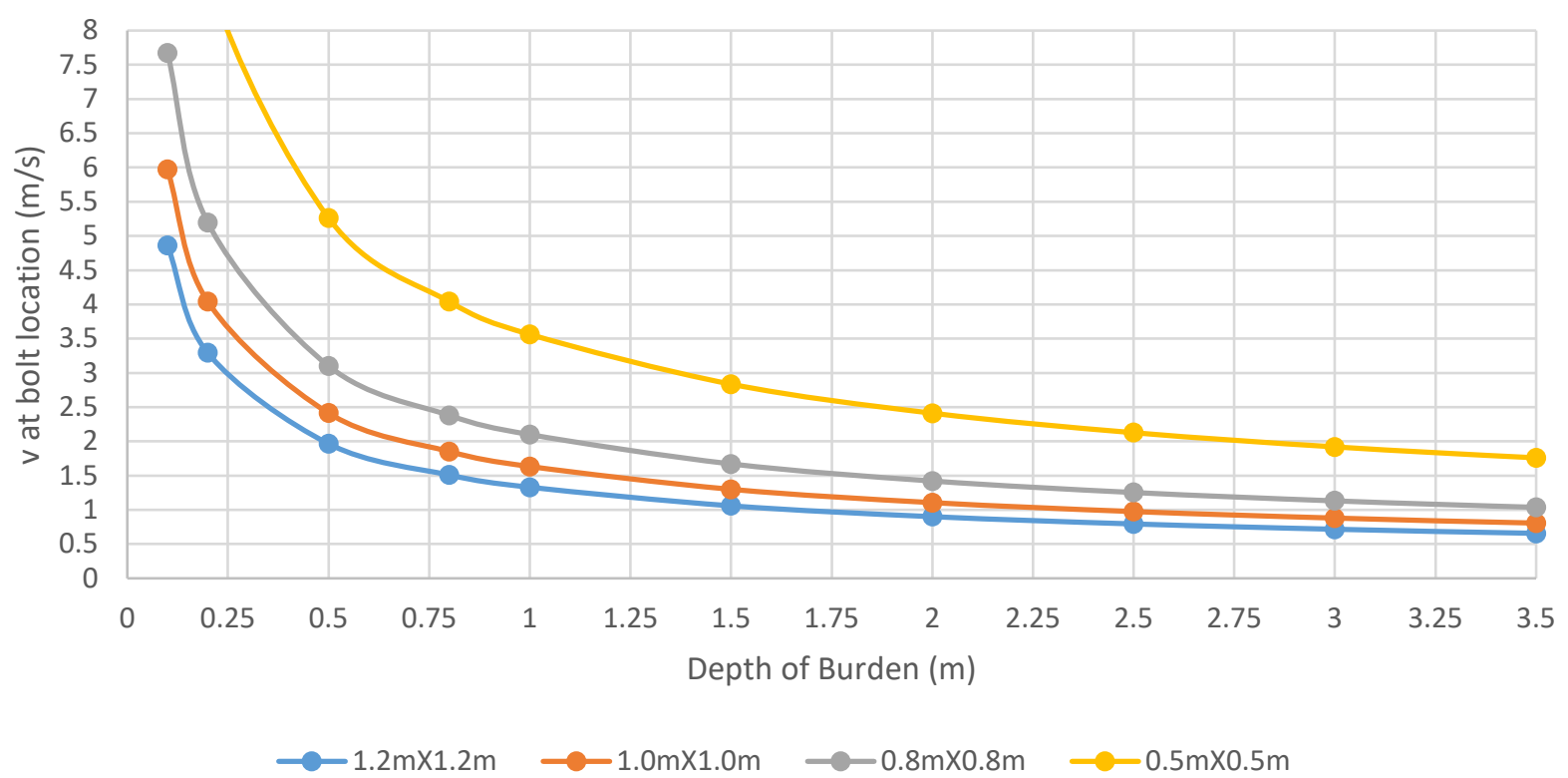

Figure 17 Direct dynamic loading rheological model example: cable bolt maximum load of $260 \mathrm{kN}$ and rock density of $2.7 \mathrm{t} / \mathrm{m}^{3}$

\section{Conclusion}

A rheological model was proposed to derive the maximum displacement capacity, energy absorption and forces of an idealised tendon support system submitted to dynamic loading. The approach may use data from POTs or materials specifications from rockbolt distributors. The approach uses data that is commonly required for the assessment of ground support systems under static loading. It provides a solution that permits greater transparency on factors influencing the performance of tendon support systems under dynamic loading. The approach also offers the estimation of energy losses outside the tendon itself, which can be verified through impact testing. 


\section{Acknowledgement}

Thanks to Newmont Goldcorp for permission to publish this paper. I wish to acknowledge Patrick Andrieux, Brad Simser and Don Peterson, who in the nineties, sought to better understand the performance of tendon support under dynamic loading using laboratory and field equipment and who have agreed to transfer the testing equipment to me at Noranda Technology Centre for further research. Thank you also to Peter Kaiser and Sean Maloney for designing and fabricating the impact test rig, which was subsequently modified for use at NTC and later at CAMNET-MMSL Bells Corners lab. Thanks to Rob Bewick, Peter Kaiser and Matt Sullivan for the many valuable discussions pertaining to this update of the rheological model to assess the likely performance of tendon support under dynamic loading.

\section{References}

Amiss, JM, Jones, FD \& Ryffel, HH 2000, Machinery's Handbook Guide 26, Industrial Press, South Norwalk.

ASTM International 2006, Standard Specification for Steel Strand, Uncoated Seven-wire for Prestressed Concrete (A416), ASTM International, West Conshohocken.

Aydan, Ö 2018, Rock Reinforcement and Rock Support, CRC Press, Boca Raton.

Aziz, N, Mirzaghorbanali, A, Nemcik, J, Heemann, K \& Mayer, S 2015, 'Shear strength properties of plain and spirally profiled cable bolts', Canadian Geotechnical Journal, vol. 52, no. 10, pp. 1490-1495.

Aziz, N, Pratt, D \& Williams, R 2003, 'Double shear testing of bolts', in Aziz, N (ed.), Coal 2003: Coal Operators' Conference, University of Wollongong, Wollongong, and The Australasian Institute of Mining and Metallurgy, Melbourne, pp. 154-161.

CSA Group 2014, Carbon Steel Bars for Concrete Reinforcement CSA G30.18-09 (R2014), CSA Group, Toronto.

Chen, Y 2014, 'Experimental study and stress analysis of rock bolt anchorage performance', Journal of Rock Mechanics and Geotechnical Engineering, vol. 6, no. 5, pp. 428-437.

Chen, Y, \& Li, CC 2015, 'Performance of fully encapsulated rebar bolts and D-bolts under combined pull-and-shear loading', Tunnelling and Underground Space Technology, vol. 45, pp. 99-106.

Derrick, WR \& Grossman, SI 1987, A First Course in Differential Equations with Applications, 3rd edn, West Publishing Company.

Engel, PA 1978, Impact Wear of Materials, Elsevier Scientific Publishing Company, 339 p.

Gaudreau, D 2004, Performance Assessment of Tendon Support Systems Submitted to Dynamic Loading, ProQuest Dissertations Publishing, École Polytechnique de Montréal, Montréal.

Gaudreau, D, Aubertin, M \& Simon, R 2004, 'Performance assessment of tendon support systems submitted to dynamic loading', in E Villaescusa \& Y Potvin (eds), Proceedings of the Fifth International Symposium on Ground Support in Mining and Underground Construction, A.A. Balkema, Rotterdam, pp. 299-312.

Gibowicz, SJ 1993, An Introduction to Mining Seismology, Academic Press, Cambridge, 399 p.

Gillerstedt, P 1999, Full Scale Pull- and Shear Laboratory Tests of Conebolts, unpublished, Boliden Ltd.

Grasselli, G 2005, '3D behaviour of bolted rock joints: experimental and numerical study', International Journal of Rock Mechanics and Mining Sciences, vol. 42, no. 1, pp. 13-24.

Kaiser, PK \& Cai, M 2012, 'Design of rock support system under rockburst condition', Journal of Rock Mechanics and Geotechnical Engineering, vol. 4, no. 3, pp. 215-227.

$\mathrm{Li}, \mathrm{CC}$ 2010, 'A new energy-absorbing bolt for rock support in high stress rock masses', International Journal of Rock Mechanics and Mining Sciences, vol. 47, no. 3, pp. 396-404.

Li, CC \& Doucet, C 2012, 'Performance of D-bolts under dynamic loading', Rock Mechanics and Rock Engineering, vol. 45, no. 2, pp. 193-204.

Li, CC, Stjern, G \& Myrvang, A 2014, 'A review on the performance of conventional and energy-absorbing rock bolts', Journal of Rock Mechanics and Geotechnical Engineering, vol. 6, no. 4, pp. 315-327.

Li, L 2016, Investigation into Shear Performance of Rock Bolts under Static and Dynamic Loading Conditions, PhD thesis, UNSW, Sydney.

Mase, GE 1970, Continuum mechanics, Schaum's outline series, McGraw-Hill, New York, pp. 196-216.

Normet, 2014, D-bolt Technical Data Sheet, Normet, viewed 19 May 2019, https://www.normet.com/wp-content/uploads/ 2016/09/D-Bolt-TDS-20140129.pdf

Plouffe, M, Anderson, T \& Judge, K 2008, 'Rock bolts testing under dynamic conditions at CANMET-MMSL', Proceedings of the 6th International Symposium on Ground Support in Mining and Civil Engineering Construction, Symposium Series S, vol. 51, South African Institute of Mining and Metallurgy, Johannesburg, pp. 581-595.

Player, J, Villaescusa, E \& Thompson, AG 2008, 'An examination of dynamic test facilities', Australian Mining Technology Conference, The Australasian Institute of Mining and Metallurgy, Melbourne.

Standards Australia 2001, AS/NZS 4671-2001: Steel Reinforcing Materials, Standards Australia, Sydney.

Thomas, GB \& Finney, RL 1992, Calculus and Analytic Geometry, 8th edn, Addison-Wesley Publishing Company, Boston.

Van Sint Jan, M 1994, 'A procedure to design tunnel support for rockburst conditions', International Workshop on Applied Rockburst Research, Santiago, pp. 277-286. 